\title{
Laboratory Test Derived Flag
}

National Cancer Institute

\section{Source}

National Cancer Institute. Laboratory Test Derived Flag. NCI Thesaurus. Code C83304.

An indication or description that laboratory test data is a derived value. 